\title{
A combination of traditional learning and e-learning can be more effective on radiological interpretation skills in medical students: a pre- and post-intervention study
}

\author{
Ali Salajegheh* ${ }^{*}$, Alborz Jahangiri, Elliot Dolan-Evans and Sahar Pakneshan
}

\begin{abstract}
Background: The ability to interpret an X-Ray is a vital skill for graduating medical students which guides clinicians towards accurate diagnosis and treatment of the patient. However, research has suggested that radiological interpretation skills are less than satisfactory in not only medical students, but also in residents and consultants.

Methods: This study investigated the effectiveness of e-learning for the development of X-ray interpretation skills in pre-clinical medical students. Competencies in clinical X-Ray interpretation were assessed by comparison of pre- and post-intervention scores and one year follow up assessment, where the e-learning course was the 'intervention'.

Results: Our results demonstrate improved knowledge and skills in X-ray interpretation in students. Assessment of the post training students showed significantly higher scores than the scores of control group of students undertaking the same assessment at the same time.

Conclusions: The development of the Internet and advances in multimedia technologies has paved the way for computer-assisted education. As more rural clinical schools are established the electronic delivery of radiology teaching through websites will become a necessity. The use of e-learning to deliver radiology tuition to medical students represents an exciting alternative and is an effective method of developing competency in radiological interpretation for medical students.
\end{abstract}

Keywords: Blended learning, Radiology, Interpretation, Medical education

\section{Background}

The ability to interpret an X-Ray is a vital skill for medical students, as this imaging modality guides the medical professional towards accurate diagnosis and treatment of a variety of conditions. However, radiological interpretation skills may be less than satisfactory in not only medical students, but also in registrars and consultants [1-9]. With the advancement of imaging technology, medicine is increasingly relying on the unsurpassed anatomical and pathological information provided by radiology, and medical students must be

* Correspondence: a.salajegheh@griffith.edu.au

School of Medicine, Menzies Health Institute Queensland, Griffith University, Gold Coast Campus, Gold Coast, QLD 4222, Australia able to extract pertinent clinical information from radiological images.

Formal teaching time in medical school devoted to the interpretation of radiological images is lacking. The duration of specific, pre-clinical radiology teaching in Australian medical schools averages $4 \mathrm{~h}$ a year [10]. These statistics are disappointing, as imaging can be utilised as a dynamic teaching utility, demonstrating anatomy, pathology and physiology [11]. Radiology is typically introduced to medical students in their clinical years [12], when they are confronted with radiological images alongside technical questions from senior doctors. This format may be inadequate to ensure optimal radiology learning, and it may be more beneficial for 
both students and clinicians that medical students are introduced to radiology as a subject earlier in their training. However, due to the 4-year postgraduate medical degree prevailing in Australian medical schools, it may be unfeasible to introduce additional didactic teaching for radiology to an already condensed program.

The use of e-learning to deliver radiology tuition represents an exciting alternative. E-learning allows students to perfect their skills in a stress-free, nonjudgemental environment [13]. E-learning increases the possibilities for more dynamic interactivity and feedback between teacher and student [14], whilst making education generally more accessible and allowing the learner to work through the content at their own pace [15]. Radiology lends itself particularly well to implementation on a computer-based format due to the highly visual nature of the content [16].

One of the current issues with radiology-focused educational materials that are available on-line is that they are generally not standardised nor specifically designed to test determined competencies. Medical students have recognised these flaws in current, freely available online radiology modules [17]. However, when e-learning has been specifically designed for medical students and constructed in an interactive manner, this learning modality has been effective in developing competency in radiological interpretation for medical students [18]. Due to the great promise for e-learning teaching modalities to revolutionise education in the future [19], the primary aim of this study was to further investigate the effectiveness of e-learning for the development of $x$-ray interpretation skills in pre-clinical medical students.

\section{Methods}

\section{Subjects}

Students were first and second year students from the Griffith University Bachelor of Medicine/Bachelor of Surgery Program, a 4-year graduate entry program with admission via GAMSAT, grade-point average and interview hurdles. First year students who participated in the study (57/152; $37 \%$ response) were allocated to the 'intervention group' receiving the e-learning course; whilst current second year students who participated (66/148; $44 \%$ response) were the 'control group' who did not receive e-learning. Both intervention group and control group participated in our traditional formal radiological education activity that included an introductory lecture about how to interpret a chest X-ray followed by a small-group practical workshop where they practiced and developed their skills by studying different chest X-rays. Participants all gave informed consent prior to the experiment via an online form, which was approved by the Griffith University ethics committee for its conduct and publication (MED/23/12/ HREC).

\section{Intervention}

The e-learning package (intervention) was developed to enhance students' competencies in clinical X-ray interpretation. The package was developed as an online interactive webpage within the university website. The program was freely accessible online via the Blackboard suite with the use of the student's university username and password. On front page of the online package ,objectives of the activity were described. This included common understanding of the techniques used for obtaining a proper chest X-ray. Terms such as inspiration, penetration, and rotation were explained followed by examples of different images of those terms. Anatomy of the respiratory system was then described and demonstrated with figures of overlapping images of different elements of respiration with the actual chest X-ray. A common method of interpretation was then introduced to the students to develop a consistent and thorough technique for reading images and learn how the silhouette sign can help localize pathology. The final stage of the online package was demonstration of interactive images of different lung and respiratory system pathological lesions that could be recognised and identified by $\mathrm{X}$-ray. Each image had a phase of plan image where no information was provided and then an image with full description and arrows showing the location, shape and forms of the pathology. From a long list of diseases presented pulmonary oedema, tuberculosis, fractured rib, diaphragmatic hernia and solitary pulmonary nodules were few of the popular examples. The X-ray e-learning package allowed pupils to explore the relevant anatomy and pathology that can be demonstrated with radiological imaging in a series of high-quality X-Ray images and associated teaching material.

\section{Assessment}

X-ray interpretation skills were assessed at three time points in the study through an online multiple-choice questionnaire of thirty questions, with four possible answers and 2 min to complete each question. Questions were designed by an expert in radiology and checked with multiple qualified confederates.

At the conclusion of the study, participants were invited to complete a questionnaire assessing their satisfaction with the e-learning course using a 5-point Likert scale, in relation to the quality, accessibility, effectiveness and organisation of the online package, especially in comparison with didactic lecture-based learning. Students were also asked to complete free text responses to aspects of the e-learning course. 


\section{Structure}

For the intervention group, the e-learning course was made available a week before the start of formal radiological teaching that included a lecture and one smallgroup workshop. Prior to being able to access the elearning course, students were required to complete a pre-intervention questionnaire as detailed above. A week after the lecture and workshop classes, the intervention group was again administered a questionnaire (postintervention assessment 1 ).

Participants in the control group completed the same questionnaire as the pre-intervention questionnaire of the intervention group. These participants had free access to the e-learning program after the completion of the study.

One year after the initial study, a follow up set of questionnaire was again administered to ensure that any meaningful variation in the marks collected from the control group were not affected by the time lapse of the delivered material in that cohort. Therefore, students in the intervention group were again invited to participate in another online multiple-choice questionnaire (postintervention assessment 2).

\section{Data analysis}

All data was entered in to the statistical analysis software, Statistical Package for Social Sciences (SPSS version 22.0, IBM, New York, NY, USA). Final data was analysed using paired and independent t-tests and ANOVA (using LSD correction). Significance threshold was taken at $p \leq 0.05$.

\section{Results}

\section{Response rate}

For the first year cohort, fifty-seven students out of one hundred and fifty-seven participated in the preintervention test, a response rate of $37.5 \%$. Forty-two students then participated in the post-intervention test 1 , a response rate of $27.6 \%$ and Forty-one students participated in the post-intervention test 2 , a response rate of $26.9 \%$.

For the second year cohort, sixty-six students out of one hundred and forty-two participated in the test, a response rate of $44 \%$.

\section{Assessment results}

Scores from the MCQ tests for the control and intervention groups are presented in Table 1 . The results indicate that students in the intervention group improved their X-ray interpretation skills from prior to the elearning course (mean score of $57.9 \%$ ) to after implementation (mean score of $70 \%$ ), and this improvement was found to be statistically significant $(p<0.05)$.

Following e-learning, students in the intervention group scored higher in the MCQ test compared to participants in the control group who did not receive the e-learning course. Post-intervention scores for the intervention group (mean score of $70 \%$ ) was higher than the solitary MCQ for the control group (mean score of $63.2 \%)$, and this difference was statistically significant $(p<0.05)$.

Furthermore, the follow up MCQ test after one year revealed that although there was a slight insignificant drop in the mean score of the second post-intervention assessment (mean score of $66.7 \%$ ), students in the intervention group maintained their X-ray interpretation skills and still achieved significantly higher marks that the control group $(p<0.05)$ (Fig. 1).

\section{Feedback results}

Tables 2 and 3 show the responses to the Likert scale statements from the first-year students (intervention group) and second year students (control group). Analysis of participants' answers demonstrates that a majority of students $(65.9 \%)$ found the on-line course to be effective in guiding them through the learning process. An overwhelming proportion $(86.4 \%)$ of the students also found the X-ray online package to be well organised, and importantly, most of the students $(71.4 \%)$ indicated that the e-learning modality engaged them in learning.

Arguably of most relevance to this study, results of the student feedback show that a large majority of students (71.4 \%) felt that the e-learning package was effective in helping them learn the art of interpreting X-rays. 71.4 \% of students were also satisfied with the quality of the online learning activity.

\section{Analysis of free text responses}

Students were invited to comment on the most useful and engaging parts of the online learning package. In total, an average of thirty-two (32) students responded

Table 1 X-Ray interpretation scores (presented as percentage with \pm standard deviation)

\begin{tabular}{lcll}
\hline & Pre-intervention MCQ & Post-intervention MCQ & One year after intervention \\
\hline Intervention group & $57.9 \pm 9.7$ & $70 \pm 4.6$ & $66.7 \pm 5.8$ \\
Control group & $60.3 \pm 9.6$ & N/A & N/A \\
\hline
\end{tabular}

Comparison of the scores (presented as percentage with \pm standard deviation), of the participants in control group ( $n=66)$ with the study cohort with intervention (pre-intervention, $n=57$, post-intervention, $n=42$ and a year after intervention, $n=41$ ) 


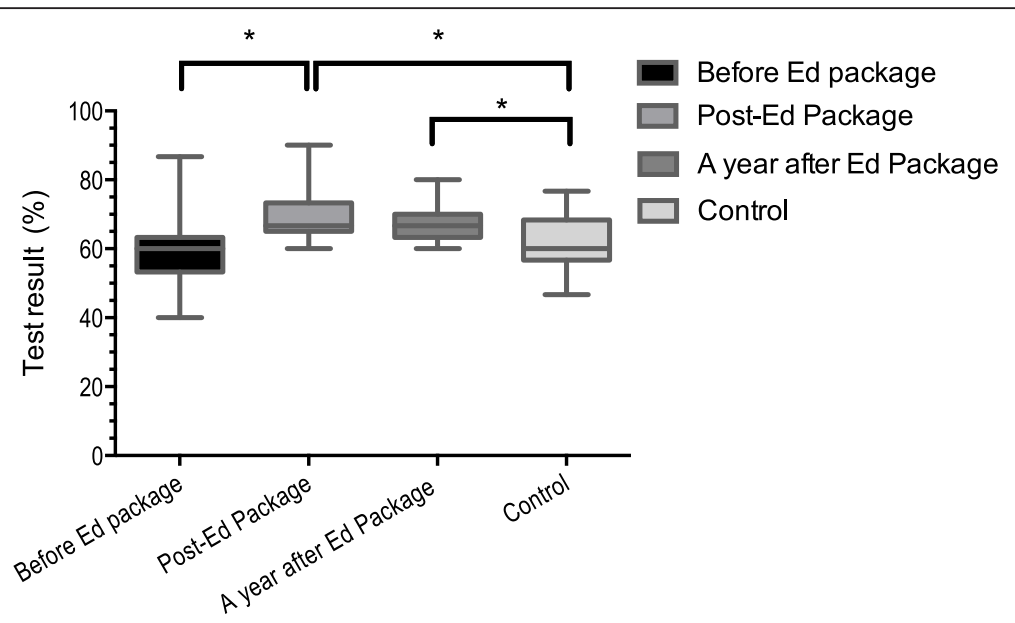

Fig. 1 On-line test results in the study group before and after intervention compared with control cohort. Test result in the study group before and after delivery of the educational package (Ed Package) and one year after the activity in comparison with similar control cohort without the online educational package showed a significant improvement in the test scores after the intervention in the study group $(p<0.05)$. The one year after intervention test revealed that the intervention helped students maintain their knowledge significantly better compared to the control group without intervention $(p<0.05)$. Asterisks $\left(^{*}\right)$ show the significant changes

to the free text portion of the survey. There were three major themes that were raised by the students, where $31 \%$ appreciated the resource, $15 \%$ identified clinically relevant learning as the best aspect of the resource, and $12 \%$ enjoyed the quantity of films available. Table 4 shows the key themes identified in the comments.

\section{Discussion}

Basic radiology interpretation is a key skill for medical students [20]. However, in most medical schools radiology training is not formally introduced until clinical rotations
[11]. Prior studies have demonstrated less than satisfactory interpretation skills in medical students, which may contribute to a high rate of incorrect statements found in clinical radiology report [17]. Indeed, incompetence in $x$ ray interpretation has been shown to lead to management errors and adverse patient outcomes [16], which indicate that more effective training is needed in this vital area [4].

Acquisition of radiological skills can come from a number of sources [12]. Due to its highly visual nature, radiology lends itself particularly well to online learning on multimedia devices. Advances in multimedia technologies

Table 2 Responses to 14 Likert scale questions related to interpretation of chest X-ray educational activity

\begin{tabular}{|c|c|c|c|}
\hline \multirow[t]{2}{*}{ Likert scale questions } & \multicolumn{2}{|l|}{ Mean } & \multirow[t]{2}{*}{ Significance } \\
\hline & Study group & $\overline{\text { Control }}$ & \\
\hline $\begin{array}{l}\text { 1. How effective was the large group resource session in preparing you for what you } \\
\text { had to do in this session? }\end{array}$ & 3.50 & 1.91 & NS \\
\hline $\begin{array}{l}\text { 2. How effective was the lecturer in relating the large group resource session's learning } \\
\text { objectives to the clinical practice workshop? }\end{array}$ & 3.55 & 3.96 & 0.003 \\
\hline 3. How effective was the lecturer in guiding you through the experiential learning process? & 3.51 & 4.29 & NS \\
\hline 4. My facilitator covered all the objectives of this session? & 4.37 & 4.29 & NS \\
\hline 5. My facilitator used approaches that helped me to learn? & 4.56 & 4.47 & NS \\
\hline 6. My facilitator was motivating and inspiring me to learn? & 4.40 & 4.36 & NS \\
\hline 7. My facilitator has highlighted the relevance of what I have to learn? & 4.26 & 4.53 & NS \\
\hline 8. My facilitator assessed my prior knowledge before explaining new material & 3.72 & 4.28 & NS \\
\hline 9. My facilitator was ensuring that I received feedback which helped me to learn? & 4.05 & 4.30 & NS \\
\hline 10. My facilitator explained the requirements and standards of work for excellence? & 3.61 & 4.21 & NS \\
\hline 11. My facilitator helped me to extend my knowledge understanding and skills (i.e. challenging me) & 4.19 & 4.54 & NS \\
\hline 12. My facilitator was helping me to learn in an organized, coherent and well-ordered manner? & 4.24 & 4.51 & NS \\
\hline 13. My facilitator was using feedback to improve his/her facilitation? & 3.46 & 4.40 & NS \\
\hline 14. My facilitator was effective in helping me to learn overall? & 4.36 & 4.55 & NS \\
\hline
\end{tabular}


Table 3 First year evaluation (intervention group) of the e-learning package

\begin{tabular}{|c|c|c|}
\hline & Number of responders & Percentage of responders \\
\hline \multicolumn{3}{|c|}{ The X-ray online package was well-organized $(n=44)$} \\
\hline Strongly agree & 12 & $27.3 \%$ \\
\hline Agree & 26 & $59.1 \%$ \\
\hline Neutral & 4 & $9.1 \%$ \\
\hline Disagree & 2 & $4.5 \%$ \\
\hline Strongly disagree & 0 & $0 \%$ \\
\hline \multicolumn{3}{|c|}{$\begin{array}{l}\text { How effective was the } X \text {-ray on-line package in guiding you } \\
\text { through the experiential learning process? }(n=44)\end{array}$} \\
\hline Very effective & 3 & $6.8 \%$ \\
\hline Effective & 26 & $59.1 \%$ \\
\hline Neutral & 7 & $15.9 \%$ \\
\hline Ineffective & 8 & $18.2 \%$ \\
\hline Very ineffective & 0 & $0 \%$ \\
\hline \multicolumn{3}{|c|}{$\begin{array}{l}\text { This component ( } X \text {-ray interpretation on-line learning package) } \\
\text { engaged me in learning }(n=44)\end{array}$} \\
\hline Strongly agree & 9 & $20.5 \%$ \\
\hline Agree & 25 & $56.8 \%$ \\
\hline Neutral & 8 & $18.2 \%$ \\
\hline Disagree & 2 & $4.5 \%$ \\
\hline Strongly disagree & 0 & $0 \%$ \\
\hline \multicolumn{3}{|c|}{$\begin{array}{l}\text { Overall, how effective was this component in helping you learn how to } \\
\text { interpret X-rays? }(n=42)\end{array}$} \\
\hline Very effective & 11 & $26.2 \%$ \\
\hline Effective & 19 & $45.2 \%$ \\
\hline Neutral & 11 & $26.2 \%$ \\
\hline Ineffective & 1 & $2.4 \%$ \\
\hline Very ineffective & 0 & $0 \%$ \\
\hline \multicolumn{3}{|c|}{ Overall, I am satisfied with the quality of this learning activity $(n=42)$} \\
\hline Strongly agree & 9 & $21.4 \%$ \\
\hline Agree & 21 & $50 \%$ \\
\hline Neutral & 9 & $21.4 \%$ \\
\hline Disagree & 3 & $7.1 \%$ \\
\hline Strongly disagree & 0 & $0 \%$ \\
\hline
\end{tabular}

have eased time pressures on educators and has paved the way for computer-assisted education [16]. Evidence is also emerging that highlights the preference students have for computer-assisted learning when compared to reference books [21].

This study has demonstrated that learning radiology online is not only a more effective method, but also highly appreciated by students. Novice students improved significantly on $\mathrm{x}$-ray interpretation scores following implementation of an e-learning $x$-ray interpretation course, scoring more highly on $x$-ray interpretation tests than students who did not receive e-learning. The students in the control group only experienced workshop and lecture teaching on $\mathrm{x}$-ray interpretation, which the intervention group also received; and even though they were ahead in their studies by a year compared to the intervention group at the time of assessment, they performed worse than the group that received the online learning. This result is consistent with other evidence that has demonstrated implementation of online learning decreased the number of failing students [7], and that for radiography learning, students who experience computer-based learning score better in radiological assessment compared to ones who learn from a textbook [22, 23].

Three key themes emerged from the students' freetext responses to the post-intervention survey: (1) students appreciated the online resource, (2) they found it clinically relevant, and (3) there was a sufficient quantity of X-rays to learn from. Other studies have also shown that students have a positive attitude towards on-line learning for radiology [24]. This feedback from students is very important as it indicates the level to which students will access, and continue to access, this learning medium to enhance their skills in radiological interpretation. As most medical students have access to a personal computer, students are comfortable using computer-based information resources for their learning. A majority of students may even prefer online courses over using textbooks [25]. Having an e-learning package available will allow pre-clinical students to hone their interpretation skills in a risk free environment at their own pace in preparation for clinical work [13].

With the progress of modern technology, there has been a significant increase in the use of simulation

Table 4 Key themes identified from free text student responses for online-learning $x$-ray package

\begin{tabular}{lll}
\hline Key issue & Number of similar responses & Sample comments \\
\hline Appreciated the resource & 10 & 'Thank you, I found this activity to be very useful' \\
$\begin{array}{ll}\text { Clinically relevant learning } \\
\text { Quantity of X-Rays }\end{array}$ & 5 & 'I liked that the examples were given in the context of a patient' \\
& $\begin{array}{l}\text { 'Lots of examples of Pathology on X-Ray } \\
\text { I think that it's important for 1st year med students as we just need } \\
\text { to see more and more X-Rays' }\end{array}$ \\
\hline
\end{tabular}


technology for teaching and assessment in medical education, which has provided additional opportunities for learning around the compact curriculum [13]. E-learning modules have a number of advantages over the standard didactic approach that is familiar to most classrooms, such as the ability to learn at anytime and anywhere, without having to travel or take time off other commitments during business hours for live classes [15]. Simulation via e-learning also allows students to hone their skills in a risk-free environment [13], and the learner is able to spend more time on certain subjects or skip others that they already know [15], allowing an increased autonomy in the educational experience for the student. However, it is important that the actual content of the elearning is interactive and attempts to simulate real clinical scenarios. In a recent study by Tan and colleagues [26], the authors implemented an e-learning program that was an online recording of lectures and compared the performance of this group with that of one who experienced didactic teaching in the classroom. In this study, students scored similar results in e-learning versus lectures. This suggests that just because content is made available online, it doesn't necessarily make it a better teaching tool than if it was available directly. It is important that the actual content of the e-learning is addressed, ensuring that students are challenged to think clinically by the program and apply their knowledge.

\section{Conclusion}

As more rural clinical schools are established in Australia and New Zealand, and the participation in courses by correspondence becomes anecdotally more popular with students, the electronic delivery of medical and health teaching will become a great priority [27]. The results of this study demonstrate that implementing radiological education through electronic means improved knowledge and skills in X-ray interpretation for students who participated in the online learning tool. Year 1 students showed a statistically significant improvement in X-ray interpretation skills following implementation of an e-learning $\mathrm{x}$-ray interpretation package. Assessment of the postintervention Year 1 students also showed scores that were statistically significantly better than the scores of Year 2 students who did not receive the intervention. With the exception of access to the online e-learning tool, the Year 2 students teaching and learning experience was the same as that of the Year 1 students. Further research is required to determine if the improved skills in X-ray interpretation is sustained in those students who have benefitted from the e-learning tool.

Competing interests

The authors declare that they have no competing interests.

\section{Authors' contributions}

AS conceived the idea for the paper from the workshop series that he is running regularly in the school of medicine. He designed the study, was involved in ethics application, data collection, analysis and write up of the paper in addition to running the workshops. AJ and SP provided the resources for the online package, the MCQs, marking criteria and draft collection. ED-E has been involved with the ethics application, advertisement of the research work in the school and data collection. All authors read and approved the final manuscript.

\section{Authors' information}

Dr. Ali Salajegheh is a medical practitioner and medical educator. He is senior lecturer in medical education and the stream lead of physical examination skills at Griffith University, School of Medicine. He has been involved in medical research throughout his career with major interest in medical education in addition to cancer molecular biology.

Dr. Alborz Jahangiri is a medical practitioner, University lecturer, and a radiology registrar. He has been involved in many different research project in the field of radiology and medical education.

Dr. Elliot Dolan-Evans is a recent medical graduate who has an interest in student advocacy and improving medical education through his roles in various student societies. He currently has strong research interests in cancer, neuroscience and medical education. In recognition of his work in this area, Elliot has received many awards for his leadership potential.

Dr. Sahar Pakneshan is a medical practitioner, lecturer and associate academic manager Years 3 and 4 at Griffith University, School of Medicine. She has been involved in many different research project in the school of medicine in the field of medical education.

\section{Acknowledgments \\ Authors would like to acknowledge Professor Gary Rogers for his constructive review and fruitful comments on this paper. Authors would also like to thank two special staff at Griffith University School of Medicine, Mr. Kelvin Upton for preparation of workshops and the clinical skills facility and Mr. Jacob Sharples for brilliant online design and constant support.}

\section{Received: 15 December 2015 Accepted: 28 January 2016

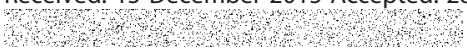

\section{References}

1. Jeffrey DR, Goddard PR, Callaway MP, Greenwood R. Chest radiograph interpretation by medical students. Clin Radiol. 2003;58:478-81.

2. Benger JR, Lyburn ID. What is the effect of reporting all emergency department radiographs? Emerg Med J. 2003;20:40-3.

3. Dawes TJW, Vowler SL, Allen CMC, Dixon AK. Training improves medical student performance in image interpretation. Br J Radiol. 2004;77:775-6.

4. Eisen LA, Berger JS, Hegde A, Schneider RF. Competency in chest radiography. A comparison of medical students, residents, and fellows. J Gen Intern Med. 2006;21:460-5.

5. Feigin DS, Smirniotopoulos JG, Neher TJ. Retention of radiographic anatomy of the chest by 4th-year medical students. Acad Radiol. 2002;9:82-8.

6. Gatt ME, Spectre G, Paltiel O, Hiller N, Stalnikowicz R. Chest radiographs in the emergency department: is the radiologist really necessary? Postgrad Med J. 2003;79:214-7.

7. Grosvenor LJ, Verma R, O'Brien R, Entwisle JJ, Finlay D. Does reporting of plain chest radiographs affect the immediate management of patients admitted to a medical assessment unit? Clin Radiol. 2003;58:719-22.

8. Kuritzky L, Haddy RI, Curry RW. Interpretation of chest roentgenograms by primary care physicians. South Med J. 1987;80:1347-51.

9. Scheiner JD, Noto RB, McCarten KM. Importance of radiology clerkships in teaching medical students life-threatening abnormalities on conventional chest radiographs. Acad Radiol. 2002;9:217-20.

10. Subramaniam RM, Kim C, Scally P. Medical student radiology teaching in Australia and New Zealand. Australas Radiol. 2007;51:358-61.

11. Mirsadraee S, Mankad K, McCoubrie P, Roberts T, Kessel D. Radiology curriculum for undergraduate medical studies-a consensus survey. Clin Radiol. 2012;67:1155-61.

12. Branstetter BF, Faix LE, Humphrey AL, Schumann JB. Preclinical medical student training in radiology: the effect of early exposure. AJR Am J Roentgenol. 2007;188:9-14. 
13. Scalese RJ, Obeso VT, Issenberg SB. Simulation technology for skills training and competency assessment in medical education. J Gen Intern Med. 2008; 23 Suppl 1:46-9.

14. Pinto A, Brunese L, Pinto F, Acampora C, Romano L. E-learning and education in radiology. Eur J Radiol. 2011;78:368-71.

15. Sendra-Portero F, Torales-Chaparro OE, Ruiz-Gomez MJ. Medical students' skills in image interpretation before and after training: a comparison between 3rd-year and 6th-year students from two different medical curricula. Eur J Radiol. 2012;81:3931-5.

16. Dikshit $A$, Wu $D$, Wu $C$, Zhao W. An online interactive simulation system for medical imaging education. Comput Med Imaging Graph. 2005;29:395-404.

17. Nyhsen CM, Steinberg LJ, O'Connell JE. Undergraduate radiology teaching from the student's perspective. Insights Imaging. 2013:4:103-9.

18. Thurley P, Dennick R. Problem-based learning and radiology. Clin Radiol. 2008;63:623-8.

19. Carriero A, Bonomo L, Calliada F, Campioni P, Colosimo C, Cotroneo A, et al. E-learning in radiology: an Italian multicentre experience. Eur J Radiol. 2012;81:3936-41.

20. O'Brien KE, Cannarozzi ML, Torre DM, Mechaber AJ, Durning SJ. Training and assessment of CXR/basic radiology interpretation skills: results from the 2005 CDIM Survey. Teach Learn Med. 2008;20:157-62.

21. Peterson C. Factors associated with success or failure in radiological interpretation: diagnostic thinking approaches. Med Educ. 1999;33:251-9.

22. Maleck M, Fischer MR, Kammer B, Zeiler C, Mangel E, Schenk F, et al. Do computers teach better? A media comparison study for case-based teaching in radiology. Radiographics. 2001;21:1025-32.

23. Gutmark R, Halsted MJ, Perry L, Gold G. Use of computer databases to reduce radiograph reading errors. J Am Coll Radiol. 2007:4:65-8.

24. Meckfessel S, Stuhmer C, Bormann KH, Kupka T, Behrends M, Matthies H, et al. Introduction of e-learning in dental radiology reveals significantly improved results in final examination. J Craniomaxillofac Surg. 2011;39:40-8.

25. Vuchkova J, Maybury T, Farah CS. Digital interactive learning of oral radiographic anatomy. Eur J Dent Educ. 2012;16:e79-87.

26. Tan P-L, Hay DB, Whaites E. Implementing e-learning in a radiological science course in dental education: a short-term longitudinal study. J Dent Educ. 2009;73:1202-12.

27. Subramaniam RM, Gibson RN. Radiology teaching: essentials of a quality teaching programme. Australas Radiol. 2007;51:42-5.

\section{Submit your next manuscript to BioMed Central and we will help you at every step:}

- We accept pre-submission inquiries

- Our selector tool helps you to find the most relevant journal

- We provide round the clock customer support

- Convenient online submission

- Thorough peer review

- Inclusion in PubMed and all major indexing services

- Maximum visibility for your research

Submit your manuscript at www biomedcentral.com/submit

) Biomed Central 